\title{
Impertinências entre trabalho, formação docente e o referencial de competências
}

\author{
Impertincences between work, teacher training \\ and the competency referential
}

\author{
Impertinencias entre trabajo, formación docente \\ y el marco de competencias
}

MONICA RIBEIRO DA SILVA*

Universidade Federal do Paraná, Curitiba- PR. Brasil.

\begin{abstract}
RESUMO: Neste artigo nos propomos a problematizar o referencial com base em competências na definição dos currículos da formação de professores. Fazemos, inicialmente, uma análise dessa abordagem situando sua origem no campo do trabalho em geral. Em seguida, discutimos a relação entre BNCC, formação de professores e o modelo de competências, considerando a experiência brasileira e sua retomada nos documentos atuais de políticas curriculares. Concluímos pela impertinência desse referencial, considerando, sobretudo, seu caráter economicista e reducionista.
\end{abstract}

Palauras-chave: BNCC e formação de professores. Modelo de competências. Currículo e competências. Trabalho e formação docente.

\begin{abstract}
In the article we propose to problematize the referential based on competences in the definition of teacher training curricula. We initially analyze this approach by locating its origin in the general field of work. Next, we discuss the relationship between BNCC, teacher training and the competency model, considering the Brazilian experience and its resumption in the current documents of curricular policies. We conclude by the impertinence of this referential, considering, above all, its economistic and reductionist feature.
\end{abstract}


Keywords: BNCC and teacher training. Curriculum and competencies model. Teacher work and training.

RESUMEN: En este artículo, proponemos problematizar el marco basado en competencias en la definición de los currículos de la formación de profesores. Inicialmente, analizamos este enfoque ubicando su origen en el campo del trabajo en general. Luego, discutimos la relación entre la Base Nacional Común Curricular (BNCC), la formación docente y el modelo de competencias, considerando la experiencia brasileña y su reanudación en los documentos actuales de políticas curriculares. Concluimos por la impertinencia de este referencial, considerando, sobre todo, su carácter economicista y reduccionista.

Palabras clave: BNCC y formación de profesores. Modelo de competencias. Currículo y competencias. Trabajo y formación docente.

\section{Introdução}

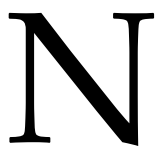

a audiência pública realizada no Conselho Nacional de Educação (CNE), em 06 de maio de 2019, cuja pauta trataria de nova Resolução sobre formação de professores, pelo menos uma intenção foi anunciada: a de que, na reformulação das diretrizes curriculares nacionais para as licenciaturas, com vistas a adequá-las às prescrições da Base Nacional Comum Curricular (BNCC), aquele órgão tomará como referência central a abordagem do currículo por competências.

Os textos da BNCC retomam uma perspectiva que já esteve presente nos documentos elaborados pelo Ministério da Educação (MEC) e pelo CNE nos anos finais da década 90, seguindo a tendência de outros países, e que se tornou conhecido como "modelo de competências" ou "formação baseada em competências".

Neste texto nos propomos a analisar a origem dessa abordagem e situar suas proposições, oriundas do campo do trabalho e da educação profissional, em meio ao cenário internacional de reconfiguração produtiva, apontando as consequências na formação dos trabalhadores. Analisamos, também, a apropriação desse referencial pela política curricular nacional, incluindo a relativa à formação docente. Situamos, por fim, esse debate no bojo da formulação atual das políticas curriculares em torno da BNCC e discutimos as consequências dessas aproximações. 


\section{Formação para o trabalho e o modelo de competências}

Segundo Hirata (1994), o modelo de competências é originário do discurso empresarial, que se firma em meados da década de 80, tendo sido retomado por economistas e sociólogos, na França, ao longo dos anos 90, com vistas a compor um repertório para orientar a formação dos trabalhadores. Já naquele momento, eram apontados os riscos da imprecisão desse referencial quando comparado ao conceito de qualificação profissional, um dos conceitos chaves da Sociologia do Trabalho. As razões para o redirecionamento da formação para o trabalho, naquele contexto, estavam relacionadas às mudanças no terreno da gestão organizacional das empresas e também nas transformações tecnológicas em que processos informatizados passam a compor os meios de produção.

A Organização Internacional do Trabalho (OIT), por meio do Centro Interamericano de Investigação e Documentação sobre Formação Profissional (Cinterfor), produziu extensa literatura sobre esse contexto, conferindo centralidade à ideia de formação com base na definição de um repertório de competências requeridas por uma dada profissão ou exercício laboral. Segundo esse órgão, a adoção do modelo de competências significaria uma possibilidade efetiva de elevação do nível de competitividade das empresas, ao mesmo tempo em que permitiria melhorar as condições de ingresso e permanência no trabalho (OIT/CINTERFOR, 1997). A “competência” seria, assim, definida como capacidade produtiva de um indivíduo (OIT/CINTERFOR, 1997).

No marco das transformações dos processos produtivos, com ecos sobre o trabalho, sobressai a necessidade de ser mais competitivo. A maior competitividade não se restringiria, no entanto, às empresas, mas, também, aos indivíduos, o que, segundo a Cinterfor, demandaria uma formação capaz de prepará-los para a "aquisição de conhecimentos fundamentais, de habilidades sociais e das atitudes que permitam enfrentar situações de contingência, assim como transferir seu saber-fazer e seu saber-ser a distintos contextos; este seria o sentido do modelo de competências" (OIT/CINTERFOR, 1997).

A formação para a competência profissional era, então, apresentada como aquela que prepararia o indivíduo para "resolver problemas":

Competência significa resolver um problema e alcançar um resultado com critérios de qualidade, isto exige que o ensino seja de tipo integral: que combine conhecimentos gerais e específicos com experiências de trabalho. As vantagens de um currículo orientado à resolução de problemas são: a) se leva em conta a forma de aprender; b) se concede maior importância a ensinar a forma de aprender do que a assimilação de conhecimentos; c) se logra maior pertinência que no enfoque baseado em disciplinas e especialidades acadêmicas; e d) se ganha maior flexibilidade do que com outros métodos. A formação baseada em normas de competência laboral facilita a educação pela alternância, permitindo ao indivíduo transitar entre a aula e a prática do trabalho, ademais estimula a formação contínua dos trabalhadores e propicia que as empresas respondam às expectativas de seu pessoal do ponto de vista da remuneração face às competências alcançadas (MerTens, 1997, p. 37). 
Caberia, assim, às instituições formativas dar conta das demandas do setor produtivo, tendo em vista "atenderem aos vazios existentes e melhorarem as condições de qualificação e emprego dos diversos setores da população" (Mertens, 1997, p. 28). Desse modo, as mudanças no sistema escolar adquiriam, claramente, o sentido de "ajuste estrutural que implica as reformas do Estado no plano político-institucional e no plano econômico-administrativo" (FRIGOTTO, 1998, p. 01).

Mertens (1997, p.28) situa as múltiplas e variadas experiências com o fim de adaptar os processos de formação profissional às mudanças o campo do trabalho. Ainda que essas experiências não tenham se desenvolvido do mesmo modo em diferentes países, é possível identificar em comum: a maior aproximação entre os sistemas de formação profissional e os de educação formal; ações no sentido de se articular a educação escolar ao setor produtivo, justificadas em função das necessidades deste último; o aparecimento de novas formas de formação profissional com vistas a potencializar os recursos já disponíveis; a integração da formação profissional ao emprego de novas tecnologias e outras inovações que demandam a participação ativa dos trabalhadores, especialmente quanto à pesquisa e desenvolvimento e, por último, uma vinculação entre capacitação e ganhos trabalhistas. $\mathrm{O}$ autor observa que se implementaram pelo menos três modelos na definição de políticas de educação profissional apoiadas no referencial de competências: os que têm as mudanças nos processos de formação para o trabalho impulsionadas pelas autoridades governamentais; os que surgem e são regulados pelas forças do mercado; e as que são empreendidas por organizações empresariais e sindicais. Sinaliza, porém, que não existem modelos puros, mas que na prática observam-se diferentes combinações. Dentro do primeiro modelo situa, por exemplo, a Grã-Bretanha, a Austrália e o México. Com predominância do segundo modelo estariam os Estados Unidos e, do terceiro, Alemanha, França e Canadá (Mertens, 1997, p. 37).

A Alemanha, desde o início dos anos 70, vinha se ocupando em definir normas e programas de formação para a competência profissional: "possui competência quem dispõe dos conhecimentos, destrezas e atitudes necessários para exercer uma profissão, pode resolver os problemas profissionais de forma autônoma e flexível, está capacitado para colaborar em seu entorno profissional e na organização do trabalho" (www.cinterfor. org.uy). Nesse país, as competências profissionais eram classificadas em quatro grandes categorias: competência técnica (domínio especializado das tarefas e dos conteúdos do trabalho, bem como dos conhecimentos e habilidades necessários para exercê-lo); competência metodológica (transferibilidade de conhecimentos e experiências de uma situação para outra; capacidade de solucionar problemas e lidar com imprevistos); competência social (saber colaborar com outras pessoas de forma comunicativa e construtiva; comportamento orientado ao grupo); competência participativa (saber participar na organização de seu espaço de trabalho e de seu entorno profissional) (STEFFEN, 2001). 
Na Espanha, a noção de competência profissional começou a ser usada na década de 80, com a constituição do Sistema Nacional de Qualificação Profissional (SNQP). O Instituto Nacional de Emprego (Inem) descreve que "as competências profissionais definem o exercício eficaz das capacidades que permitem o desempenho de uma ocupação, com respeito aos níveis requeridos no emprego". (www.cinterfor.org.uy). Segundo esse órgão, as capacidades profissionais são definidas tanto pelo exercício de uma atividade quanto pelos comportamentos e condutas necessários para seu desempenho. $\mathrm{O}$ perfil do trabalhador está subdivido em competência geral, unidades de competência, realizações profissionais e critérios de desempenho.

No sistema inglês, em virtude das prescrições do Conselho Nacional para Qualificação Vocacional (NCVQ), a noção de competências encontra-se difusa em uma estrutura de normalização. O sistema inglês definiu cinco níveis de competência para que se pudesse diferenciar o grau de autonomia dos trabalhadores: a variabilidade, a responsabilidade diante dos recursos, a aplicação de conhecimentos básicos, a amplitude e alcance das destrezas, a supervisão do trabalho e a transferibilidade de um espaço de trabalho a outro.

Nos Estados Unidos as proposições próximas ao modelo de competências estão associadas às características de uma produção de alto rendimento. Segundo Steffen (2001), “a produção de alto rendimento está diretamente vinculada às novas formas de organização do trabalho e se baseia principalmente no critério de que o incremento da qualidade, produtividade e flexibilidade pode obter-se mediante uma utilização mais eficaz da força de trabalho". Nesse país, a Secretary's Comission on Achieving Necessary Skills (Scans), definiu, na década de 90, três categorias de habilidades consideradas básicas no processo de formação do trabalhador e cinco categorias de competências referenciadas pelo desempenho no processo de trabalho. As basic-skills podem ser traduzidas como "habilidades básicas (ler, escrever, calcular, ouvir, falar), as thinking skills, como 'habilidades de raciocínio (criar, decidir, resolver problemas, etc.), e as "qualidades pessoais", pautadas em critérios como responsabilidade, autoestima, sociabilidade e integridade (DEFfUnE e DePresbiteris, 1997, p. 29).

No México, o Conselho Nacional de Normalização e Certificação de Competência Profissional (Conocer) define competências como: "capacidade produtiva de um indivíduo que se define e mede em termos de desempenho em um determinado contexto de trabalho, e não somente de conhecimentos, habilidades, destrezas e atitudes; estes são necessários mas insuficientes por si mesmos para um desempenho efetivo". (www.cinterfor.org.uy). Nesse país, as competências requeridas pelo mercado de trabalho estão subdivididas em competências básicas (condutas elementares associadas à formação prévia como capacidade de leitura, expressão e comunicação verbal e escrita); competências genéricas (associadas a desempenhos comuns em diversas atividades) e competências específicas (associadas a conhecimentos de caráter técnico). 
No Canadá, o modelo de competências começa a ser definido no final dos anos 60, em vista do desenvolvimento industrial e da necessidade de melhorar as habilidades e destrezas da força de trabalho. Nesse contexto, e com apoio do governo, forja-se a Formação Baseada em Competências. A educação deveria guiar-se pelo que é esperado do estudante ao término da escolarização. Dentre as experiências realizadas nesse país, destaca-se o Programa Dacum (Designing a Curriculum ou Developing a Curriculum). As competências requeridas para desempenho profissional estão classificadas em: competências acadêmicas (saber ler, escrever, falar, resolver problemas e ter disposição para a aprendizagem contínua); competências de desenvolvimento pessoal (motivação, autoestima, confiança); e competências para trabalhar em equipe. É conferida especial importância para as habilidades fundamentais, tais como: leitura, escrita, comunicação oral, habilidades de raciocínio, memória etc.

Na Argentina, o Conselho Federal de Cultura e Educação define competências como "um conjunto identificável e evoluível de conhecimentos, atitudes, valores e habilidades relacionados entre si que permitem desempenhos satisfatórios em situações reais de trabalho, segundo padrões utilizados na área ocupacional". (www.cinterfor.org.uy). Essa definição reporta-nos a uma outra característica que vinha se delineando no âmbito da abordagem curricular por competências: a de que a conduta em termos de valores é condição de exercício qualitativo do trabalho e que a subjetividade possa ser controlada e dirigida aos requisitos de maior responsabilidade, comportamento ético e criatividade que possam geram maior produtividade e competitividade.

A Austrália concebe competências como "uma complexa estrutura de atributos necessários para o desempenho de situações específicas. É uma complexa combinação de atributos (conhecimento, atitudes, valores e habilidades) e as tarefas que se tem que desempenhar em determinadas situações". (www.cinterfor.uy). A normalização de competências nesse país obedece à seguinte classificação: competências industriais (relacionadas a uma área ocupacional específica); competências transversais (comuns a várias áreas ocupacionais); competências gerais ou genéricas (sinalizam o desempenho do trabalhador) e as competencias chave, consideradas fundamentais para o bom desempenho no trabalho e tidas como qualidades da vida adulta (STEFFEN, 2001).

Na França, na década de 80, foi criado o Rome (Repertório Operacional de Ofícios e Empregos), que integra em menos de 500 famílias profissionais os ofícios no país. Foi elaborado com base na execução de um inventário de atividades por função transformadas em competências (Deffune e Depresbiteris, 1997). Nesse contexto, o termo competências é compreendido como: "o saber mobilizar conhecimentos e qualidades para fazer frente a um dado problema, ou seja, as competências designam conhecimentos e qualidades contextualizados" (Mandon apud Stroobants, 1997). Em 1990 foi formalizada a CAP 2000 (Conduta da Atividade Profissional), que introduz a gestão da produção com base em competências (Ramos, 2001, p. 94). 
Desse levantamento acerca da incorporação do modelo de competências em diferentes países, depreende-se que não se trata de um modelo unitário de formação para o trabalho. Da análise realizada, no entanto, é possível constatar um conjunto de elementos comuns que aproxima as distintas normalizações: a associação com o desempenho (performance) de modo a ampliar a competitividade; uma ênfase na prática, no uso dos saberes tácitos adquiridos no fazer do trabalho; a subordinação do conhecimento ao que é "utilizável" com vistas a aumentar a produtividade; a consolidação de mecanismos capazes de dimensionar essa produtividade e exercer maior controle sobre a atividade de trabalho.

No Brasil, o Ministério do Trabalho e o Ministério da Educação nem sempre convergiram quanto aos sistemas de formação, normalização e certificação de competências. Naquele contexto, a produção do discurso oficial sobre formação profissional, especialmente no interior da Secretaria de Formação Profissional (Sefor) do Ministério do Trabalho, foi sendo balizada pela disseminação da ideia de que "trabalhador qualificado é imune ao desemprego" (Moraes, 1999, p. 25).

No Documento Certificação de Competências Profissionais: pontos em torno dos quais se busca a convergência, elaborado pelo Ministério do Trabalho, o termo competências adquire uma multiplicidade de sentidos:

As competências como sendo aptidões, habilidades e conhecimentos que garantem um potencial de capacidades adquiridas e inclinações inatas que, bem direcionadas, permitem o perfeito desempenho das performances exigidas pelo mercado de trabalho;

As competências como sendo uma lista de realizações ou atividades que estão sendo exigidas na ponta do sistema empregatício com a indicação precisa das normas e padrões de exigências e desempenho mínimo para o exercício satisfatório para cada posto de trabalho. O indivíduo competente, no caso, seria aquele que possui as qualificações adequadas para atingir o desempenho ótimo exigido no posto de trabalho;

As competências como sendo o resultado de uma longa e vivenciada experiência somente adquirida na prática intensa de um ofício e dificilmente transmissível de um profissional a outro;

A competência seria um conceito com um forte componente social e político, variando conforme o contexto e a situação vivida pelo profissional, sendo em grande parte uma responsabilidade individual, única e original, dificilmente construída apenas por processos educativos. (apud STEFFEN, 2001).

Outro foco disseminador do modelo de competências no Brasil foi a Secretaria de Educação Média e Tecnológica. A Semtec tomava como principal referência para a educação profissional as Diretrizes Curriculares Nacionais para essa modalidade de ensino. No Parecer CNE/CEB nº 16/99, competência profissional é definida como "capacidade de articular, mobilizar e colocar em ação valores, conhecimentos e habilidades necessários para o desempenho eficiente e eficaz de atividades requeridas pela natureza do trabalho". Nota-se uma semelhança entre esta conceituação e as presentes no âmbito das prescrições da OIT/Cinterfor. 
Ferretti (1997) explica a adoção do "modelo de competência" como uma alternativa conveniente para o campo empresarial, que ora é contraposto ao conceito de qualificação, ora usado como seu sinônimo. Salienta, no entanto, que possuem conotações diferentes. Competência "enfatiza menos a posse de saberes técnicos e mais a sua mobilização para a resolução de problemas e o enfrentamento de imprevistos na situação de trabalho, tendo em vista a maior produtividade com qualidade". Por enfatizar as condições individuais de produtividade, traz consequências para a relação capital-trabalho, como o favorecimento da negociação e do envolvimento em detrimento do embate e dos posicionamentos críticos.

Manfredi (1998) afirma que a ideia de qualificação estaria sendo substituída ou englobada pela noção de competências e que estes termos têm passado por um processo de ressignificação. As razões disso estariam nas transformações técnico-organizacionais que ocorreram no mundo do trabalho e que têm suscitado novos debates em torno das relações entre trabalho, qualificação e educação. A autora chama a atenção para o fato de que este processo tem gerado uma ressignificação das noções de trabalho, formação profissional, qualificação e competência. Observa que a noção de competência é utilizada desde os anos 70 pelas ciências da cognição e da linguística e passa a ser incorporada ao discurso empresarial e administrativo, bem como por cientistas sociais. A autora nota ainda que o emprego da noção de competência faz-se de forma indistinta nos campos da educação e do trabalho como se fosse capaz de comportar uma conotação universal. Ela representa, no entanto, uma atualização da Teoria do Capital Humano ${ }^{1}$ com vistas a reintegrar os trabalhadores ao processo de reestruturação produtiva.

Em face do exposto evidencia-se uma tendência que se manifestou na substituição do conceito de qualificação pela noção de competências, um movimento justificado pela busca da maior competitividade que apostava no desempenho do trabalhador para firmar seus parâmetros. Consolida-se, desse modo, uma racionalidade que se fundamenta no mercado (de produção, de consumo e de trabalho) e gera um tipo de formação orientada por critérios economicistas. É preciso ter claro que a adoção do modelo de competências pela reforma educacional brasileira do pós-LDB de 1996 foi anunciada, reiteradas vezes, como necessária, tendo em vista a adequação do processo de escolarização a mudanças ocorridos nos processos produtivos. Nesse sentido, é possível afirmar que houve uma subordinação da formação humana aos imperativos de adequação a demandas postas pela via unilateral do mercado de trabalho. Firma-se, assim, uma perspectiva economicista de formação, decorrente do emprego de critérios, pressupostos e métodos próprios da economia, isto é, do mundo da produção de mercadorias e serviços, na definição dos processos formativos e das políticas a eles vinculados. Em que medida esses elementos guardam pertinência quando se trata de formular a política nacional de formação de professores? 


\title{
O modelo de competências na formação de professore
}

\begin{abstract}
A LDB de 1996, ao afirmar no Art. 26 a necessidade de uma base nacional comum para a educação básica, levou o Conselho Nacional de Educação a exarar um conjunto de resoluções, compondo as Diretrizes Curriculares Nacionais para todas as etapas e modalidades da educação básica. Em sequência, a Câmara de Educação Superior dá início a um processo de formulação de Diretrizes Curriculares para os cursos de graduação. Nesses dois momentos se apresenta como referencial para a organização dos currículos o já referido "modelo de competências". No Brasil, esse referencial compôs, especialmente para o ensino médio e para os cursos superiores, os fundamentos e propostas para a definição de planos curriculares.

Dos enunciados nos documentos oficiais foi possível identificar uma falta de clareza e de unicidade nas conceituações, o que teve, como consequência, uma compreensão parcial e fragmentada das normatizações. Nos Parâmetros Curriculares Nacionais para o Ensino Médio, competências está definida como:

capacidade de abstração, do desenvolvimento do pensamento sistêmico ao contrário da compreensão parcial e fragmentada dos fenômenos, da criatividade, da curiosidade, da capacidade de pensar múltiplas alternativas para a solução de um problema, ou seja, do desenvolvimento do pensamento divergente, da capacidade para trabalhar em equipe, da disposição para procurar e aceitar críticas, da disposição para o risco, do desenvolvimento do pensamento crítico, do saber comunicar-se, da capacidade de buscar conhecimento. Estas são competências que devem estar presentes na esfera social, cultural, nas atividades políticas e sociais como um todo, condições para o exercício da cidadania neste contexto (BRASIL, MEC, 1999).
\end{abstract}

No Parecer CNE/CEB 15/98 que estabelece as Diretrizes Curriculares Nacionais para Ensino Médio:

A formação básica a ser buscada no ensino médio se realizará mais pela constituição de competências, habilidades e disposições de condutas do que pela quantidade de informações. Aprender a aprender e a pensar, relacionar o conhecimento com dados da experiência cotidiana, a dar significado ao aprendido e a captar o significado do mundo, a fazer a ponte entre teoria e prática, a fundamentar a crítica, a argumentar com base em fatos, a lidar com o sentimento que a aprendizagem desperta (BRASIL, CNE, 1998).

A preocupação com a formação e preparo dos professores de modo a adequar suas práticas aos direcionamentos postos pelos Parâmetros e Diretrizes Curriculares Nacionais para a educação básica estava explícita também nas diretrizes para a formação docente. No texto Proposta de Diretrizes Curriculares para a Formação de Professores, a noção de competências também é tomada como referência e, nesse caso, indica-se:

A concepção de competência é nuclear na orientação do curso de formação inicial de professores. As competências tratam sempre de alguma forma de atuação, só existem "em situação" e, portanto, não podem ser aprendidas apenas pela comunicação de ideias. Para construí-las, as ações mentais não são suficientes - ainda que 
sejam essenciais. Não basta um profissional ter conhecimentos sobre seu trabalho; é fundamental que saiba fazê-lo. (BrasIL, MEC, 2001)

No texto das Diretrizes Curriculares Nacionais para a Formação de Professores da Educação Básica, em Nível Superior (BRASIL, CNE, 2002), assim se estabelece:

\begin{abstract}
Art. $3^{o}$ A formação de professores que atuarão nas diferentes etapas e modalidades da educação básica observará princípios norteadores desse preparo para o exercício profissional específico, que considerem:

I - a competência como concepção nuclear na orientação do curso;

II - a coerência entre a formação oferecida e a prática esperada do futuro professor.
\end{abstract}

É evidente a referência ao discurso que vinha se consolidando no campo do trabalho e da educação profissional em geral. Essa compreensão de competência, como algo que se constrói "na ação", certamente explica as iniciativas voltadas para dentro da escola com ênfase em suas "práticas", como se estas fossem dissociadas de um corpus teórico. Indica, também, a intenção de garantir que os indicativos da reforma curricular na educação básica ultrapassassem a mera comunicação de intenções e chegassem, de maneira afirmativa, ao que é efetivamente praticado. Por essa razão tornava-se central adotar o mesmo referencial para os cursos de Licenciatura. Tais proposições vieram, no entanto, acompanhadas da crítica. Sobretudo devido ao caráter economicista e pragmático circunscrito ao modelo de competências.

Lopes (s.d.) e Macedo $(2000,2002)$ lembram que, na década de 70, a perspectiva intitulada ensino para a competência decorreu da influência das teorias da eficiência social sobre o currículo e esteve, de início, associada à formação de professores, mas acabou por adentrar outras modalidades de ensino. Nessa perspectiva, o termo competência substituía a descrição de objetivos, no entanto, tal qual a pedagogia por objetivos, estabelecia um elenco de comportamentos mensuráveis, com a intenção de serem cientificamente controláveis. Lopes assim analisa a vertente mencionada:

A ideia, ainda muito presente no senso comum educacional de uma forma mais ampla, de que a qualidade do desenvolvimento curricular, e da educação de uma forma geral, depende de uma definição precisa dos objetivos a serem implementados e, por conseguinte, do perfil de profissional, de cidadão ou de sujeito social que se pretende formar, deriva do pensamento de que o currículo existe para atender às finalidades sociais do modelo produtivo dominante. Tal perspectiva nega a possibilidade de que os fins educacionais sejam estabelecidos no desenvolvimento das atividades curriculares. Ao contrário, encara que a definição dos objetivos, a partir de uma concepção empírico-positivista de ciência, pode estabelecer o controle neutro do trabalho realizado. Por isso o caráter comportamental de um objetivo é defendido, na medida em que o comportamento do aluno, como expressão objetiva, sem ambiguidades e inequívoca do produto do processo educacional, garantiria a possibilidade de avaliação da eficiência desse processo (LOPES, s.d.). 
Lopes e Dias (2003) analisaram o uso do referencial de competências nas políticas de formação de professores no Brasil, na década de 90, a partir do campo da teoria curricular. As autoras situam essa apropriação como um retorno a propostas que datam da década de 60 e que era decorrente, ao final do século XX, da influência que movimentos e reformas educacionais em países centrais exercem sobre países periféricos, e que, no presente caso, tal influência estaria sendo exacerbada devido ao processo de globalização econômica e mundialização da cultura. No texto Lopes e Dias identificam os EUA como o país em que mais esteve presente a ideia de eficiência docente e a produzir pesquisas sobre o assunto. Asseveram que foi a partir daí que se originou o movimento de formação baseado em competências, "cujo principal objetivo era a formação do professor eficiente para atender às necessidades que estavam postas pela sociedade" (p. 1161). As pesquisas que daí resultaram associam eficiência e eficácia docente à formação de professores com base na definição de um repertório de descrição de atitudes e destrezas dos futuros professor. Muito próximo, portanto, do movimento que se propaga ao longo das três últimas décadas do século passado e que constituiu o chamado modelo de competências tratado na seção 1 deste artigo.

\section{Considerações finais}

O estudo realizado permitiu identificar associações estreitas entre a formação para o trabalho em geral e a formação para o trabalho docente, a partir da consolidação do referencial de competências. $\mathrm{O}$ chamado modelo de competências se origina e se alimenta de uma perspectiva economicista dos processos formativos, assentada em critérios de eficiência, produtividade e competitividade, que culminam por conferir ênfase ao desempenho e a uma concepção de prática, dissociada de seus fundamentos teóricos, dando espaço para um reduzido saber-fazer.

As aproximações entre competências no campo do trabalho em geral (trabalho produtivo) e as políticas da formação de professores trazem como consequência uma perspectiva reducionista e limitadora da formação e do trabalho docente, seja pela primazia de um saber-prático, em detrimento da articulação entre teoria e prática, seja pela ênfase no desempenho, tornando secundário o processo, essencial na composição de um percurso formativo sólido e abrangente.

Em que pese a crítica já realizada em torno do modelo de competências, a retomada dessa perspectiva, seja pela política curricular nacional para a educação básica inscrita nos documentos da BNCC, seja no anúncio de sua referência para compor novas diretrizes nacionais para a formação de professores, reitera um movimento já vivenciado no País, vale dizer, sem que se tenha traduzido em melhoria da qualidade de ensino. A ênfase no desempenho culminou com a produção expressiva de exames nacionais e subordinação 
da política educacional a imperativos das avaliações em larga escala, nacionais e internacionais, como é o caso do Pisa (Programa Internacional de Avaliação de Estudantes), organizado pela OCDE (Organização para Cooperação e Desenvolvimento Econômico). Essa lógica reitera uma formulação, que toma o currículo em sentido limitado, como taxionomia que prioriza a prescrição de objetivos de aprendizagem e enfatiza um aspecto da dimensão cognitiva - aquele que pode ser aferido. Secundariza, com isso, aspectos mais complexos dessa dimensão, além de concorrer para o menosprezo de outros aspectos da formação humana, de ordem intelectual, ética e estética.

Recebido em: 23/05/2019 e aprovado em: 01/06/2019

\section{Notas}

1 Essa ideia é compartilhada por outros estudiosos, dentre eles Frigotto (1995). Ao analisar o amplo contexto em que se processa a reestruturação produtiva, situando-a nos planos político, econômico, jurídico e educacional, o autor evidencia que, estrategicamente, em favor da economia capitalista, a Teoria do Capital Humano teria passado por um rejuvenescimento, e que isto representa um ajuste entre os campos econômico-social e educacional regulados pelas leis do mercado.

\section{Referências}

BRASIL. Conselho Nacional de Educação. Câmara da Educação Básica. Parecer 15/98. Diretrizes Curriculares Nacionais para o Ensino Médio. Brasília, CNE/CEB, 1998.

BRASIL. Conselho Nacional de Educação. Câmara da Educação Básica. Parecer 16/99. Diretrizes Curriculares Nacionais para a Educação Profissional. Brasília: CNE/CEB, 1999.

BRASIL. Conselho Nacional de Educação. Resolução 01/2001. Diretrizes Curriculares Nacionais para Formação de Professores. Brasília, CNE/CP, 2001.

BRASIL. Ministério da Educação. Parâmetros Curriculares Nacionais para o Ensino Médio. Brasília. MEC/SEMTEC, 1999.

BRASIL. MEC. Proposta de Diretrizes Curriculares para a formação de professores. Brasília: MEC/ INEP, 2001.

DEFFUNE, Deisi; DEPRESBITERIS, Lea. As múltiplas faces da competência. In: BRASIL. MINISTÉRIO DO TRABALHO. SECRETARIA DE FORMAÇÃO PROFISSIONAL. Educação profissional: o debate das competências. Brasília: MTB: SEFOR, 1997.

DIAS, Rosanne Evangelista; LOPES, Alice Casimiro. Competências na formação de professores no Brasil: o que (não) há de novo. Educ. Soc., Campinas, CEDES, v. 24, n. 85, p. 1155-1177, dezembro 2003. 
FERRETI, Celso João. Formação profissional e reforma do ensino técnico no Brasil: anos 90. Educação \& Sociedade, CEDES, v. 18, n. 59, agosto de 1997.

FRIGOTTO, Gaudêncio. Educação e crise do capitalismo real. São Paulo: Cortez, 1995.

FRIGOTTO, Gaudêncio. Educação e crise do trabalho: perspectivas de final de século. Petrópolis: Vozes, 1998.

HIRATA, Helena. Da Polarização das qualificações ao modelo de competências. In: FERRETI, C.; ZIBAS, D. M. L.; MADEIRA, F.R.; FRANCO, M. L. Novas Tecnologias, Trabalho e Educação. Um debate multidisciplinar. Petrópolis, Rio de Janeiro: Vozes. 1994.

LOPES, Alice Casimiro. Competências na organização curricular da reforma do ensino médio. Boletim SENAC. Disponível em www.senac-nacional.br/informativo/BTS/273/boltec273a.htm. s.d. Acesso em: 20 mar 2002.

MACEDO, Elizabeth. Formação de professores e diretrizes curriculares nacionais: para onde caminha a Educação? 23a Reunião Anual da ANPED. Caxambu, MG, 2000.

MACEDO, Elizabeth. Currículo e competência. In: LOPES, Alice Casimiro; MACEDO, Elizabeth. Disciplinas e Integração Curricular. Rio de Janeiro: DP\&A, 2002.

MANFREDI, Silvia Maria. Trabalho, qualificação e competência profissional - das dimensões conceituais e políticas. Educação \& Sociedade, Campinas, CEDES, v. XIX, n. 64, setembro, 1998.

MERTENS, Leonard. Sistemas de competência laboral: surgimiento e modelos. In: OIT/VVAA. Formación basada en competencia laboral. Montevideo: Cinterfor, 1997.

MORAES, Carmen Sylvia V. Introdução ao Documento Diagnóstico da Formação Profissional - Ramo Metalúrgico. Brasil, São Paulo: CNM/ Rede UNITRABALHO, 1999.

OIT/CINTERFOR. Formacion basada en competência laboral: situación actual y perspectivas. Montevideo: Cinterfor, 1997.

RAMOS, Marise Nogueira. Da qualificação à competência: deslocamento conceitual na relação trabalho-educação. Tese de Doutorado. Universidade Federal Fluminense Niterói, RJ, 2001.

STEFFEN, Ivo. Modelos de competência profissional. Oficina Internacional do Trabalho. Impressos do Curso Normalização, formação e certificação de competências. Belo Horizonte, 12 a 13 de março de 2001. 